\title{
Does the infection with endoparasites influence the effect of oral vaccination against classical swine fever in wild boar?
}

\author{
Anna Ondrejková ${ }^{1}$, Ondrej Kiš², Juraj Ciberej², Katarína Oberhauserová2, \\ Róbert Ondrejka ${ }^{1}$, Peter Smitka ${ }^{2}$, Tomáš Csank ${ }^{3}$
}

University of Veterinary Medicine and Pharmacy in Košice, ${ }^{1}$ Department of Epizootiology and Parasitology,

${ }^{2}$ Department of Nutrition, Dietetics and Feed Production, ${ }^{3}$ Department of Microbiology and Immunology, Košice, Slovak Republic

Received December 10, 2014

Accepted May 13, 2015

\begin{abstract}
Classical swine fever is a highly contagious viral disease that affects domestic and wild suids and could cause important economic losses. It is the most dangerous infectious disease of the wild boar that can cause severe death in densely populated areas. The aim of the study was to determine the effect of endoparasites on the oral vaccination against classical swine fever in wild boar. The study compared classical swine fever antibody titres in wild boar treated and untreated with antiparasitics. Fourteen six-month-old wild boar piglets were tested via direct ELISA to detect specific antibodies in blood serum after vaccination. Before the vaccination, one group of piglets was administered antiparasitic therapy; the other group of animals remained untreated. Twenty-eight days post vaccination, piglets from the first group (free of parasites) showed significantly $(P=0.0015)$ higher concentrations of specific antibodies than the infected animals. Obtained results proved that parasitic infections substantially influence the efficacy of oral vaccination against classical swine fever and may support the ability of the virus to produce infectious diseases and its transmission in the wild boar population. For that reason, antiparasitic therapy of wild boar populations before their vaccination is highly recommended in order to increase the vaccine's efficacy.
\end{abstract}

Hog cholera, lungworms, antibody, wild swine

Classical swine fever is caused by the classical swine fever virus (previously called Hog Cholera Virus - HCV), Flaviviridae family, Pestivirus genus; the virus belongs to RNA viruses with a high mutative ability, thus they are adaptable to environmental selective pressure. Every year, new foci of the infection are recorded in domestic and wild pigs. European countries have not yet eliminated the infection although they received various prevention and eradication measures. Nowadays, prophylactic vaccination of domestic pigs is prohibited within the European Union. The risk of classical swine fever infection has an increasing tendency in pig populations (Kleiboeker et al. 2002; Risatti et al. 2005; Podmanický et al. 2008).

Routine vaccination is an essential part of the wild boar populations' health management programme. In spite of the actual classical swine fever prevention arrangements, it is obvious that the wild boar is still a natural source of the infection. State Veterinary and Food Administration of the Slovak Republic elaborated the National Eradication Programme based on detailed analysis of long-term classical swine fever progress in the wild boar population (SVFA SR 2010). The programme includes emergency oral vaccination of wild boars.

Oral vaccination efficacy can be decreased by various factors, subsequently adding to the cost. One of them is the immunity status of the organism. It is suspected that parasites could be a factor influencing the immunity status and classical swine fever vaccination efficacy in the wild boar population. (Rajský et al. 2001; Podmanický et al. 2008).

Address for correspondence:

Assoc. Prof. MVDr. Anna Ondrejková, PhD.

Department of Epizootiology and Parasitology

University of Veterinary Medicine and Pharmacy in Košice

Komenského 73, 04181 Košice, Slovak Republic 
The aim of the study was to determine the effect of endoparasites on the oral vaccination against classical swine fever in wild boar.

\section{Materials and Methods}

\section{Experimental design}

The study included 14 wild boar piglets aged 6 months, from a wild boar reservation (Army Forests and Estates, State Company, Jovsa, Kamenica nad Cirochou) in the Michalovce District of Slovakia. The piglets were chemically immobilized using the Helabrun mixture $(125 \mathrm{~g}$ of xylazine hydrochloride and $100 \mathrm{mg}$ of ketamine hydrochloride) in order to simplify the game handling and sampling. During the first sampling, each piglet was identified with an ear-mark, and blood and faecal samples from the sinus ophtalmicus and rectum were obtained, respectively. The antiparasitic substance (Gallmectin inj. a.u.v., INVET s.r.o., Czech Republic, dose $1.5 \mathrm{ml} /$ piglet) was administered subcutaneously and (Baycox 5\%, susp. a.u.v, Bayer Animal Health, Germany, dose $20 \mathrm{mg} / \mathrm{kg}$ ) was administered per os to six piglets representing the first group of animals (Group 1). The rest of the piglets, which represent the second group of animals (Group 2), remained untreated. The oral vaccine against classical swine fever (RIEMSER ${ }^{\circledR}$ Schweinepestoralvakzine) is a live attenuated vaccine against classical swine fever for oral vaccination of wild boar based on the CSF virus (CSFV strain "C", vaccine dose containing at least $10^{4.5} \mathrm{TCID}_{50}$, Riemser Arzneimittel AG, Germany) and it was given to all piglets after remobilization. The vaccine bolls (blisters) contain approximately $1.6 \mathrm{ml}$ of vaccine suspension and they are put into bait made from corn mass in the approximate size of $4 \times 4 \times 15 \mathrm{~cm}$. The vaccine bolls were added to the feed ration and the real individual reception of each boll was monitored visually. Piglets from both groups were kept separately after anti-parasitic treatment and vaccination under controlled conditions without possible reintroduction of parasites. The anti-parasitic treatment and vaccination were performed simultaneously, the effect of anti-parasitic treatment comes $3-5$ days after administration. On the $5^{\text {th }}$ day after anti-parasitic treatment, pigs were moved into a new, cleaned, and disinfected box. The development of the immune response started from the $14^{\text {th }}$ day after vaccination. When performing oral vaccination against CSF of wild boar it is important to require a ban on hunting for 28 days (protection period for meat when using ivermectin preparations). Twenty-eight days post vaccination, the second sampling was carried out, faecal and blood samples were collected and processed identically.

The faeces and blood from both samplings were processed and stored for subsequent parasitological and serological laboratory testing. The blood samples were centrifuged to obtain blood serum that was subsequently frozen for later detection of specific classical swine fever antibodies. The faecal samples were refrigerated and transported to a parasitological laboratory to test them by coprology as fresh as possible.

\section{Parasitological study}

The faecal samples were examined parasitologically by ovoscopy (coprology, flotation according to Breza). Species composition was recorded in the samples.

\section{Counting of oocysts and eggs by Mc Master method}

The quantitative technique was used for counting oocysts and eggs in one gram of faeces (OPG/EPG). Three grams of faeces were diluted in $42 \mathrm{ml}$ of tap water, sieved into a test tube and centrifuged at $700 \times g$ for $2 \mathrm{~min}$. After removing the supernatant, a flotation solution was added, mixed, and oocysts and eggs were counted in the Mc Master chamber. The number of oocysts and eggs was multiplied by 50 to give the OPG and EPG in the faecal sample (1 gram).

\section{Serological study}

Blood sera samples were tested via direct enzyme-linked immunosorbent assay (ELISA). ELISA is a diagnostic tool for a fast and simple screening of large numbers of sera for detection of antibodies against classical swine fever. The ELISA-kit Ceditest ${ }^{\mathbb{B}}$ (Ceditest CSFV, Cedi-Diagnostics B.V. Lelystad, the Netherlands) was used to detect specific classical swine fever antibody values according to the manufacturer's recommendation. Absorbance (optical density - OD, wavelength $450 \mathrm{~nm}$ ) was measured in the processed samples by ELISA Reader Labsystems Multiskan ${ }^{\circledR}$ Plus, EFLAB Join Venture Company Labsystems and Flow Laboratories, Finland). Mean $\mathrm{OD}_{450}$ and corrected $\mathrm{OD}_{450}$ reference sera were calculated. The percentage of inhibition (PI) was solved according to the formula in the Ceditest manual. The result interpretation of PI (\%) was as follows: PI $\leq 30 \%-$ sample without specific antibodies, $\mathrm{PI}=31 \%$ - 50\% - sample must be tested by a neutralisation test; $\mathrm{PI} \geq 50 \%$ - sample with specific antibodies.

In order to detect significant differences between the two samplings, the mean percentage of inhibition (\%) was calculated and analysed statistically by PAST ( $t$-test, $P=0.0015$ ). The experiment was approved for the project No: 1/0768/10 by the Ethics Committee of the University of Veterinary Medicine and Pharmacy in Košice. 


\section{Results}

\section{Parasitological study}

After the first sampling, five species of endoparasites were detected by ovoscopy in faecal samples of all piglets included in the study, namely Metastrongylus spp. (100\%) with a mean EPG - 689, Eimeria spp. (100\%) with a mean OPG - 1393, Trichuris suis (57.14\%) with a mean EPG - 319, Oesophagostomum spp. (50\%) with a mean EPG 231 and Capillaria spp. (35.7\%) with a mean EPG - 100. Only Metastrongylus spp. and Eimeria spp. were detected in two cases from the group of six treated piglets after the second sampling (Table 1).

\section{Serological study}

According to the parasitological and serological examination, the values of specific antibodies against classical swine fever (expressed as the percentage of inhibition) were compared in wild boar piglets infected and uninfected with parasites. The difference in

Table 1. Counts of oocysts and eggs per gram of faeces from inspected wild boar piglets.

\begin{tabular}{lccc}
\hline Parasite & $\begin{array}{c}\text { Before antiparasitic therapy } \\
\text { mean EPG/OPG }\end{array}$ & $\begin{array}{c}\text { After therapy (Group 1) } \\
\text { mean EPG/OPG }\end{array}$ & $\begin{array}{c}\text { Without therapy (Group 2) } \\
\text { mean EPG/OPG }\end{array}$ \\
\hline Eimeria spp. & 1393 & 150 & 1456 \\
Metastrongylus spp. & 689 & 100 & 630 \\
Trichuris suis & 319 & 0 & 288 \\
Oesophagostomum spp. & 231 & 0 & 203 \\
Capillaria spp. & 100 & 0 & 75 \\
\hline
\end{tabular}

OPG - counts of oocysts per gram faeces

EPG - counts of eggs per gram faeces

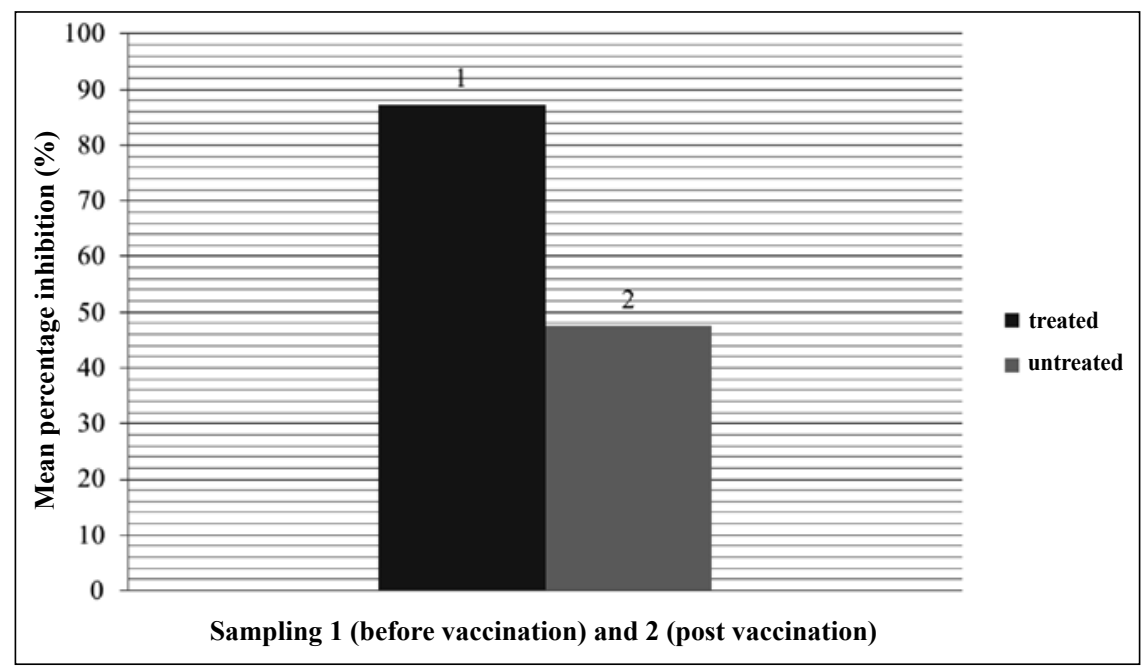

Fig. 1. Specific classical swine fever antibody increase (PI\%) after vaccination against classical swine fever in treated and untreated wild boar piglets 
the specific antibody values are expressed in Fig. 1 (as an average of the percentage of inhibition increase after the vaccination in the treated and untreated piglets). The piglets with antiparasitic therapy showed substantially higher $(P=0.0015)$ concentrations of specific antibodies (PI: 85.33, 91.27, 81.22, 83.47, 93.93, 88.14) compared to the infected animals (PI: 38.15, 43.17, 45.89, 40.72, 45.00, 42.02, 36.21, 40.92).

\section{Discussion}

Findings of the five parasite taxa have been described in the wild boar in several cases. In Slovakia, Halasz (1991) has recorded metastrongylosis in the wild boar. Metastrongylosis is one of the limiting factors of body weight increase; however, it usually progresses latently. Highly infected wild boar can be a convenient source of classical swine fever and other infections in pigs. Similarly to our study, Metastrongylus spp. was detected in wild boar in Spain (Fernandez-de-Mera et al. 2004) and in Estonia (Jaervis et al. 2008). In Poland metastrongylosis is obviously a frequent helminthosis (Popiolek et al. 2010).

Occurrence of Eimeria spp. was detected in wild boar in Estonia (Jaervis et al.2008), in Poland (Balicka-Ramisz et al. 2000; Pilarczyk et al. 2004) and also in the wild boar population in Finland (Hälli et al. 2010).

Trichuriosis is a cosmopolitan parasitosis and its occurrence in the wild boar population in Slovakia has been registered by Hovorka et al. (1993). Trichuris suis is a helminth that has been described in boar in Spain (Fernandez-de-Mera et al. 2004), in Poland (Popiolek et al. 2010), Estonia (Jaervis et al. 2008) and Iran (Eslami and FarsadHamdi 1992).

The eggs of Oesophagostomum spp. are hardly distinguishable from those of Hyostrongylus rubidus; therefore, the presence of oesophagostomosis is only suspected in this case. Oesophagostomum spp. occurs more frequently. In pigs, oesophagostomosis is a "stable helminthosis" that can be infective for wild boars. It was recorded in Poland (Popiolek et al. 2010), Spain and France (Fernandez-de-Mera et al. 2004), in Iran (Eslami and Farsad-Hamdi 1992) and the highest prevalence was described in Estonia (Jaervis et al. 2008).

Capillaria spp. is a parasite which rarely occurs in other countries. It is possible that the eggs detected in our faecal samples are the eggs of Capillaria species not specific for wild boars, but for wild ruminants or birds. The wild boar probably receives the eggs through food without the subsequent life cycle continuation. Boar can be infected with C. garfiai that is transmitted by intermediate hosts (earthworms). Only few authors mention the helminth. Löwenstein and Kutzer (1993) recorded the prevalence of C. garfiai in a range of $66.6 \%$ to $90.9 \%$.

Based on serological examination, piglets that were treated with antiparasitics showed substantially higher concentrations of specific antibodies (Prokeš et al. 2012). The study confirmed that parasitic infection affects the efficacy of oral vaccination. Based on this fact, we can suppose that parasitic infections markedly affect the pathogenicity of not only classical swine fever, but also other infectious and non-infectious diseases.

Holland et al. (2003) describe a decrease of the efficacy of oral vaccination against classical swine fever after infection with Trypanosoma evansi. Due to immunosuppression of an organism, lower concentrations of specific antibodies were detected in pigs infected by $T$. evansi compared to those not infected. This fact was explained by the reduction of T-cell responsiveness.

It is known that the basic prerequisite for high quality and good health of the wild boar population is its optimal age and social structure. The main flaw of the hunting management in Slovakia is the inappropriate shooting of piglets that causes an epizootological risk 
and breaks the social structure of the population; as well as decreasing trophy quality (Chramazda et al. 2008).

In order to prevent classical swine fever transmission, vaccination of the wild boar population is the most substantial method. The aim of oral vaccination is to increase the number of immunized animals and decrease the amount of those susceptible. A few factors can reduce the efficacy of oral immunization. One of the factors is the immunity status of an individual that can often be affected by parasitic diseases. Due to economic reasons and a high level of the wild boar reproduction rate, the eradication of parasitosis in free ranging hunting grounds is very difficult (Rajkovic-Janje et al. 2002). On the other hand, reduction of the efficacy of classical swine fever oral vaccination due to parasitic diseases can cause much higher economic losses in domestic pig husbandry infected by classical swine fever. Anthelminthic treatment is relatively simple in park and farm game breeding systems where we can administer the antiparasitic preparation directly "by hand", meaning by injection (Sudová et al. 2010). We recommend the addition of antiparasitics directly into vaccines which could be a partial solution. It is very important to inform hunters and the non-hunting community about transmission possibilities of infectious and parasitic diseases from the wild boar population to domestic pig husbandry. Because of low awareness, illegal dung-yards are frequently created which serve as suitable environment for the survival of endoparasite eggs and life stages. Thus, wild boar are infected by parasite species that are typical only for domestic pigs, which supports their subsequent transmission to wild boar population. Breeders should avoid chances of cross contact between domestic pigs and wild boar and keep all the epizootological measures (Takacs 1997). The high reproduction capacity and occurrence of wild boar in human residence surroundings increase the risk of infection transmission to domestic pig breeding (classical swine fever) as well as to humans (viral hepatitis type E). Though classical swine fever has not been recorded in Slovakia recently, we can suppose that the classical swine fever virus is still circulating in the wild boar population, and preventive management is permanently substantiated.

The obtained results proved that parasitic infections substantially influence the efficacy of oral vaccination against classical swine fever and may support the ability of the virus to produce infectious diseases and its transmission within the wild boar population. For that reason, antiparasitic treatment of wild boar populations before their vaccination is highly recommended in order to increase the vaccine efficacy.

\section{Acknowledgements}

The study was supported by the Science Grant Agency of Ministry of Education, Science, Research and Sport of the Slovak Republic VEGA No: 1/0768/10; 1/0960/12.

\section{References}

Balicka-Ramisz A, Pilarczyk B, Cisek A 2000: Protozoa from Eimeria genus in wild animals in Poland. Med Weter 56: 723-724

Chramazda V, Garaj P, Lebocký T, Sokol J, Rajský D 2008: Management of wild boar (in Slovak). Slovak Vet J 33: $42-45$

Eslami A, Farsad-Hamdi S 1992: Helminth parasites of wild boar, Sus scrofa in Iran. J Wildlife Dis 28: 316-318

Fernandez de Mera IG, Vicente J, Gortazar CH, Hofle U, Fierro Z 2004: Efficacy of an in-feed preparation of ivermectin against helminths in the European wild boar. Parasitol Res 92: 133-136

Halasz J 1991: Prevalence of metastrongylosis in wild boar (Sus scrofa L.) in Slovak Republic. Folia Venat 21: 99-111

Hälli O, Ala-Kurika E, Peltoniemi O, Heinonen M 2010: The prevalence of internal parasites in wild boar farms in Finland. Acta Vet Scand 52: 529

Holland WG, Do TT, Huong NT, Duong NT, Thanh NG, Vercruysse J, Godderis BM 2003: The effect of Trypanosoma evansi infection on pig performance and vaccination against classical swine fever. Vet Parasitol 111: $115-123$ 
Hovorka I, Hovorka J, Mituch J 1993: Helminths of wild boar in the Tatra Mts. National Park. Folia Venat 23: 69-78

Järvis T, Mägi E 2008: Pig endoparasites in Estonia. International scientific conference proceedings: Animals, Health, Food Quality: 54-58

Kleiboeker SB 2002: Swine fever: classical swine fever and African swine fever. Vet Clin N Am Food A 18: 43-451

Löwenstein M, Kutzer E 1993: The distribution and biology of Capillaria garfiai from Sus scrofa. App Parasitol 34: 51-62

SVFA SR (State Veterinary and Food Administration of the Slovak Republic): The plan of eradication of CSF in the population of wild boar in the Slovak Republic, year 2011 (in Slovak). Available at: www.svssr.sk/ dokumenty/zvierata/kmo_2011.pdf. Last modified December 2010. Accessed January 2011

Pilarczyk B, Balicka- Ramisz A, Cisek A, Syalewska K, Lachowska S 2004: Prevalence of Eimeria and intestinal nematodes in wild boar in north-west Poland. Wiad Parazytol 50: 637-640

Podmanický D, Pliešovský J, Št’astná D, Št’astný P 2008: Classical swine fever - diagnostics and prophylaxis (in Slovak). Slovak Vet J 33: 147-151

Popiolek M, Knecht D, Syczesna-Stankiewicz J, Czerwinska-Rozalow A 2010: Helminths of the wild boar (Sus scrofa L.) in natural and breeding conditions. Bull Vet Inst Pulawy 54: 161-166

Prokeš M, Zendulková D, Rosenbergová K, Treml F, Ondrejková A, Beníšek Z, Ondrejka R, Korytár L, Slepecká E, Süli J, Haladová E, Maženský D 2012:Detection of Mycoplasma hyopneumoniae by ELISA and nested PCR from blood samples and nasal swabs from pigs in Slovakia. Acta Vet Brno 81: 327-331

Rajkovic-Janje R, Bosnic S, Rimac D, Dragicevic P, Vinkovic B 2002: Prevalence of helminths in wild boar from hunting grounds in eastern Croatia. Z Jagdwis 48: 261-270

Rajský D, Janto R, Miško J 2001: Classical swine fever in wild boar and prophylaxis (in Slovak). Slovak Vet J 6: $327-332$

Risatti GR, Borca MV, Kutish GF, Lu Z, Holinka LG, Freuch RA, Tulman ER, Rock DL 2005: The E2 glycoprotein of classical swine fever virus is a virulence determinant in swine. $J$ Virol 79: $3787-3796$

Sudová E, Piačková V, Velíšek J, Pijáček M, Svobodová Z 2010: Efficacy testing of orally administered praziquantel to common carp naturally infected by Caryophyllidean tapeworms (Platyhelminthes: Eucestoda). Acta Vet Brno 79: 73-78

Takacs A 1997: Contribution to the helminth infestation in wild boar (Sus scrofa L.) in Hungary. Wien Tierarztl Monat 84: 314-316 